\title{
Balance problems after unilateral lateral ankle sprains
}

\author{
Mohammad Akbari, PhD; ${ }^{\mathbf{*}}$ Hossein Karimi, PhD; ${ }^{\mathbf{1}}$ Hossein Farahini, PhD; ${ }^{2}$ Soghrat Faghihzadeh, $\mathbf{P h D}^{\mathbf{3}}$ \\ Departments of ${ }^{1}$ Physical Therapy and ${ }^{2}$ Orthopedic Surgery, Iran University of Medical Sciences, Tehran, Iran; \\ ${ }^{3}$ Department of Biostatistics, Tarbiat Modares University, Tehran, Iran
}

\begin{abstract}
Ankle ligament injury is the most common injury in athletic activities. This study examined balance problems in athletes with acute lateral ankle sprains. Thirty male athletes aged 20 to 35 years with right dominant side and traumatic ankle sprain were recruited through simple nonprobability sampling. We measured the sway index and limits of stability with the Biodex Balance System under different conditions. Functional balance was evaluated with two clinical tests: the Functional Reach Test and the Star-Excursion Balance Test. The results showed that balance ability in patients with acute lateral ankle sprain was significantly weaker under closed- versus open-eye conditions. Symmetry of weight-bearing on involved and sound limb in bilateral standing was not significantly different, but weightbearing on the nondominant limb was significantly higher than on the dominant limb. We can conclude that balance problems occur after acute ankle sprains because of proprioception deficits and that the unconscious (reflexive) aspect of proprioception is more severely affected than the conscious (voluntary) aspect.
\end{abstract}

Key words: ankle, balance, consciousness, ligament, limits of stability, proprioception, rehabilitation, sprain, stability, sway.

\section{INTRODUCTION}

Lateral ankle sprains are the most common acute pathology seen in athletic activities [1]. Up to one-sixth of all time lost from sports is because of this type of injury [2]. Sixteen percent of all sports injuries are ankle ligament sprains [3]. The cost for treatment and rehabilitation of these injuries is $\$ 2$ billion a year [4]. Reducing the incidence of ankle ligament injuries depends on identifying the conditions under which such injuries occur (e.g., extrinsic variables, such as height and ankle-specific measures, that might predispose athletes to such injuries) [4].

Many researchers have reported that individuals with a history of ankle sprains are more susceptible to subsequent ankle sprains or chronic ankle instability [5-7]. Otter found that 73 percent of ankle sprains occur in ankles that had previously been sprained [8]. Therefore, previously sprained ankles must have some risk factors that cause them to be recurrently sprained [5]. Numerous factors and mechanisms are thought to contribute to this increased ankle sprain occurrence [9]. Some of these factors are instability, muscle weakness, limited mobility of the ankle joint, problems related to footwear, and damage to the proprioceptors in the ligaments of the ankle [6,9]. According to Michelson and Hutchins, two levels of proprioception exist: conscious (voluntary) and unconscious (reflexive). While the conscious aspect is involved in overall control during sports and activities of daily living, the unconscious aspect is involved in joint stabilization during unexpected perturbations [10]. Nashner showed that one of the main factors in reducing body sway in a standing position is proprioception [11].

\footnotetext{
Abbreviations: FRT $=$ Functional Reach Test, LOS $=$ limits of stability, ROM = range of motion, SEBT = Star-Excursion Balance Test.

* Address all correspondence to Dr. Mohammad Akbari, Department of Physical Therapy, School of Rehabilitation Sciences, Iran University of Medical Sciences, PO Box 15875-4391, Tehran, Iran; +9821-22227124; fax: +982122220946. Email: akbarimo43@yahoo.com
}

DOI: 10.1682/JRRD.2006.01.0001 
Body sway will increase if proprioception is deficient because of ligamentous injury [12]. In other words, balance will be disturbed in such cases. Balance problems can be measured by two different procedures: (1) clinical tests and (2) laboratory tests with new equipment [13]. Two examples of clinical procedures are the Functional Reach Test (FRT) and the Star-Excursion Balance Test (SEBT) [14-15]. One new piece of laboratory equipment for evaluating balance is the Biodex Balance System (Biodex Medical Systems; Shirley, New York), which can be used for measuring body sway (balance index) and determining limits of stability (LOS) [16-17]. Body sway and LOS can be measured in either bi- or unilateral standing positions. Because the ankle joint has an essential role in balance control, the location of the center of pressure depends on the ankle joint position and leg muscle (plantar flexor and dorsiflexor) activity. Balance control in unilateral standing will be disturbed in patients with functional ankle instability [16].

This study examined balance problems in athletes with Rouzier Grade I and II unilateral lateral ankle sprains. We were interested in the following questions: (1) Do any balance problems exist after traumatic ankle ligament sprain? (2) Which aspect of balance ability suffers most? (3) What are the effects of vision (open or closed eyes) on balance ability in patients with ankle sprain?

\section{METHODS}

\section{Subjects}

This study was a clinical trial that was conducted in physical therapy clinics of the Sports Medicine Federation of Iran between April 2003 and March 2004. The ethics committee of the Iran University of Medical Sciences approved the study. All subjects were informed about the procedures and signed a consent form prior to participation. The subjects were 30 male athletes involved in multidirectional sports (football, volleyball, and martial arts). These athletes with right-side dominance and Grade I and II traumatic ankle sprain (according to Rouzier grading) were aged $22.8 \pm 4.8$ years [18]. All data are presented as mean \pm standard deviation unless otherwise noted. Subjects were excluded for orthopedic and/or neurological conditions, uncorrected problems with vision, chronicity and recurrence of the sprain, and left-side dominance.

\section{Data Collection}

Data collection included subject interviews, appropriate musculoskeletal evaluations, and performance on different balance tests. Individual characteristics (age, weight, and height), job, grade of sprain, number of involved ligaments, involved side, kind of sport, date of injury, and grade of pain were recorded with a questionnaire. Ankle range of motion (ROM) was measured by goniometer. Before being tested, subjects with severe pain or joint swelling were treated to a level at which they could bear full weight, their ankle muscle strength was at least 4 according to the manual muscle test [19], and their ankle ROM was 80 percent of the normal range. Each subject participated in a training session before testing that included an explanation of the procedure and performance of different parts of the main tests. Sway index was measured with the Biodex Balance System 945-302 (Biodex Medical Systems; Shirley, New York) for bi- and unilateral standing on the involved and sound limb with eyes in the open and closed positions. LOS were measured with this system for bi- and unilateral standing on the involved and sound limb. In addition, static balance was evaluated with the FRT; a mean of three repetitions was considered. Dynamic balance was evaluated with the SEBT; a mean of five repetitions was considered.

Statistical Package for the Social Sciences, Version 10 (SPSS, Inc; Chicago, Illinois), was used for statistical analysis. We used paired $t$-tests for comparing data related to balance ability of involved and sound limbs and chisquare analyses for comparing sensitivity of the different balance tests to balance problems. An $\alpha$ level of 0.05 was set for the analyses.

\section{RESULTS}

Subjects were $22.8 \pm 4.8$ years old, $74.14 \pm 8.26 \mathrm{~kg}$ in mass, and $179.96 \pm 7.05 \mathrm{~cm}$ tall. Of the 30 subjects, 17 had a right-side sprain and 13 had a left-side sprain; 14 subjects had a Grade I and 16 had a Grade II sprain. One ligament was injured in 17 subjects, two ligaments were injured in 5 subjects, and three ligaments were injured in 8 subjects. The anterior talofibular ligament was sprained in 26 subjects, the calcaneofibular ligament in 12 subjects, and the posterior talofibular ligament in 10 subjects.

On the FRT, mean distance displaced in bilateral standing was significantly lower than unilateral standing on involved and sound limbs $(p<0.001)$ (Table 1). On the SEBT, mean distance displaced in unilateral standing on involved and sound limbs was significantly different 
(Table 1). Balance index was significantly lower for bilateral standing with eyes open compared with eyes closed $(p<0.001)$. With eyes open, balance ability for unilateral standing on involved limb was significantly lower compared with sound limb $(p<0.001)$. Balance ability for unilateral standing on sound limb was 24 percent better than on involved limb. Values for LOS for unilateral standing on involved and sound limbs were not significantly different (Table 1).

Chi-square tests showed a strong relationship between the scores of all balance tests in the study for detecting balance problems after traumatic ankle ligament sprain $(p>$ 0.90) (Table 2).

\section{DISCUSSION}

In this study, the anterior talofibular ligament was sprained in 26 subjects, the calcaneofibular ligament in 12 subjects, and the posterior talofibular ligament in 10 subjects. This result agrees with Otter's results [8]. He reported that the anterior talofibular ligament is the most commonly injured, followed by the calcaneofibular ligament. The posterior talofibular ligament is injured only in severe sprains. This pattern of ligament sprain could be attributed to such factors as ankle joint structure, mechanism of injury (inversion), and strength of ankle ligaments. The anterior talofibular ligament is the weakest of the lateral ankle ligaments, and it acts against inversion forces.

The results of the balance tests in this study indicate that after traumatic lateral ankle sprains, balance problems occur because of proprioceptive deficiency. The FRT was used for evaluating static balance. This test is a valid and reliable clinical tool for evaluation of balance. FRT in the present study for bilateral standing was $29.20 \pm 5.96 \mathrm{~cm}$ for 20- to 35-year-old males. Duncan et al. reported the normal value of that test to be $41.74 \pm 4.75 \mathrm{~cm}$ for 20 - to 40-year-old persons [20]. A significant difference was noted between the results of this study for individuals with lateral ankle sprain and subjects with no ankle injuries. Our results show that functional test values were greater

Table 1.

Comparison of mean values for sound and involved limb on different balance tests.

\begin{tabular}{lccrrr}
\hline Balance Test & $\begin{array}{c}\text { Sound Limb } \\
\text { (Mean } \pm \text { SD) }\end{array}$ & $\begin{array}{c}\text { Involved Limb } \\
\text { (Mean } \pm \text { SD) }\end{array}$ & $\mathbf{9 5 \%}$ CI & $\boldsymbol{t}$-Test & $\boldsymbol{p}$-Value \\
\hline FRT $(\mathrm{cm})$ & $34.79 \pm 7.22$ & $30.39 \pm 3.93$ & -3.44 to -5.36 & -9.38 & 0.001 \\
SEBT $(\mathrm{cm})$ & $86.80 \pm 9.34$ & $84.97 \pm 10.26$ & -0.25 to -3.42 & -2.36 & 0.025 \\
DBO & $1.84 \pm 0.46$ & $2.42 \pm 0.93$ & 0.89 to 0.26 & 3.68 & 0.001 \\
DBC & $6.63 \pm 2.38$ & $6.58 \pm 2.29$ & 0.69 to -0.80 & -1.46 & 0.885 \\
LOS (\%) & $17.6 \pm 7.6$ & $16.4 \pm 7.7$ & 0.61 to -2.95 & -1.34 & 0.192 \\
LOST (s) & $111.03 \pm 35.22$ & $122.60 \pm 41.95$ & 20.87 to 2.27 & 2.54 & 0.017 \\
WBC (kg) & $53.93 \pm 21.16$ & $46.03 \pm 21.16$ & 7.87 to -23.73 & -1.03 & 0.313 \\
WBO (kg) & $45.73 \pm 29.82$ & $55.27 \pm 29.82$ & 12.80 to -31.74 & -0.87 & 0.392 \\
\hline
\end{tabular}

$\mathrm{CI}=$ confidence interval, $\mathrm{DBC}=$ dynamic balance bilateral standing eyes closed, DBO $=$ dynamic balance bilateral standing eyes open, FRT $=$ Functional Reach Test, LOS = limits of stability, LOST = limits of stability time, $\mathrm{SD}=$ standard deviation, SEBT = Star-Excursion Balance Test, WBC = weight-bearing eyes closed, $\mathrm{WBO}=$ weight-bearing eyes open.

Table 2.

Distribution of scores on balance tests for involved limb $(N=30)$. Scores on all balance tests were divided into four groups to create classes. Number of individuals in each class was determined, and chi-square test indicated a strong relationship $(p>0.90)$.

\begin{tabular}{|c|c|c|c|c|c|c|c|c|c|c|}
\hline \multirow[t]{2}{*}{ Group } & \multicolumn{2}{|c|}{$\begin{array}{c}\text { Star-Excursion } \\
\text { Balance Test }\end{array}$} & \multicolumn{2}{|c|}{$\begin{array}{l}\text { Functional } \\
\text { Reach Test }\end{array}$} & \multicolumn{2}{|c|}{ Dynamic Balance* $^{*}$} & \multicolumn{2}{|c|}{ Limits of Stability } & \multicolumn{2}{|c|}{$\begin{array}{c}\text { Limits of } \\
\text { Stability Time }\end{array}$} \\
\hline & Class & $n$ & Class & $n$ & Class & $n$ & Class & $n$ & Class & $n$ \\
\hline 1 & 61-71 & 7 & $18-23$ & 7 & $4.7-5.6$ & 8 & $4-12$ & 7 & 193-234 & 7 \\
\hline 2 & 72-82 & 8 & $24-29$ & 10 & $3.6-4.6$ & 8 & $13-21$ & 8 & 150-192 & 8 \\
\hline 3 & 83-93 & 8 & 30-35 & 5 & $2.5-3.5$ & 7 & $22-30$ & 8 & 107-149 & 8 \\
\hline 4 & 94-104 & 7 & $36-40$ & 8 & $1.4-2.4$ & 7 & 4-12 & 7 & 64-106 & 7 \\
\hline
\end{tabular}


while subjects were standing on one limb compared with bilateral standing. This may be due to the fact that subjects use their free limb as a balancing lever during unilateral standing. However, the results indicate that static balance of athletes with ligament sprain becomes abnormal because of proprioceptive deficiency.

In comparing the results of the FRT for unilateral standing on the sound or involved limb, we noted a significant difference. The static balance on the involved limb was 12.7 percent lower than on the sound limb. The SEBT was used for dynamic balance evaluation. Mean values for the sound and involved limbs were significantly different [14].

The balance index was significantly lower for bilateral standing with eyes open compared with eyes closed. The sensorimotor system normally uses inputs from three afferent systems: vestibular, somatosensory, and visual. When one of those systems (somatosensory) is impaired, the two intact systems compensate for the impaired one to some extent. But when the subject closes his or her eyes, only one intact afferent system remains for balance control. Therefore, balance index in the eyes-closed situation becomes higher compared with eyes open [13-14,21].

With eyes open, unilateral standing balance on the involved limb was significantly lower compared with the sound limb. Balance control while subjects were standing on the sound limb was 24 percent better than on the involved limb. This result agrees with Freeman et al. [6], Nashner [11], Garn and Newton [12], Tropp and Odenrick [16], Bullock-Saxton et al. [22], Lentell et al. [9], and Leanderson et al. [23], who all reported that impairment of proprioception has a major effect on balance after lateral ankle sprains.

LOS in unilateral standing on the involved and sound limbs were not significantly different, but test duration on the sound limb was shorter than on the involved limb, which means that motor control of the involved limb was disturbed.

The results reveal that after Grade I and II lateral ankle sprains, balance problems occur and are a result of proprioceptive deficits, especially the unconscious (reflexive) part of proprioception as opposed to the conscious (voluntary) part [10]. This factor probably plays an important role in recurrence of ankle sprain. Therefore, an effective rehabilitation program for managing proprioceptive deficits should be followed.

\section{CONCLUSIONS}

From these results, we can conclude that after acute ankle sprains, the unconscious (reflexive) part of proprioception is more severely affected than the conscious (voluntary) part. In other words, improvement of the conscious part of proprioception can occur during the first month of treatment, but for improvement of the unconscious part, we have to wait about 3 to 6 months, depending on the degree of injury.

\section{ACKNOWLEDGMENTS}

This material was based on work supported by the Tarbiat Modares University, Tehran, Iran. We would also like to thank the Department of Physical Therapy of the Sports Medicine Federation of Iran, Tehran, Iran, for use of their equipment and facilities.

The authors have declared that no competing interests exist.

\section{REFERENCES}

1. Brand RL, Black HM, Cox JS. The natural history of inadequately treated ankle sprains. Am J Sports Med. 1977; 5(6):248-49. [PMID: 931035]

2. Garrick JG. The frequency of injury, mechanism of injury, and the epidemiology of ankle sprains. Am J Sports Med. 1977;5(6):241-42. [PMID: 563179]

3. Maehlum S, Daljord OA. Acute sports injuries in Oslo: A one-year study. Br J Sports Med. 1984;18(3):181-85.

[PMID: 6435714]

4. Beynnon BD, Renstrom PA, Alosa DM, Baumhauer JF, Vacek PM. Ankle ligament injury risk factors: A prospective study of college athletes. J Orthop Res. 2001;19(2): 213-20. [PMID: 11347693$]$

5. Wright IC, Neptune RR, Van den Bogert AJ, Nigg BM. The influence of foot positioning on ankle sprains. J Biomech. 2000;33(5):513-19. [PMID: 10708771]

6. Freeman MA, Dean MR, Hanham IW. The etiology and prevention of functional instability of the foot. J Bone Joint Surg Br. 1965;47(4):678-85. [PMID: 5846767]

7. Smith RW, Reischl SF. Treatment of ankle sprains in young athletes. Am J Sports Med. 1986;14(6):465-71. [PMID: 3099587

8. Otter SJ. The conservative management of lateral ankle sprains in the athlete. Foot. 1999;9(1):12-17. 
9. Lentell G, Baas B, Lopez D, McGuire L, Sarrels M, Snyder P. The contribution of proprioceptive deficits, muscle function, and anatomic laxity to functional instability of the ankle. J Orthop Sports Phys Ther. 1995;21(4):206-15. [PMID: 7773272]

10. Michelson JD, Hutchins C. Mechanoreceptors in human ankle ligaments. J Bone Joint Surg Br. 1995;77(2):219-24. [PMID: 7706334]

11. Nashner LM. Vestibular and reflex control of normal standing. In: Stein RB, Pearson KB, Smith RS, Redford JB, editors. Control of posture and locomotion. New York (NY): Plenum Press; 1973. p. 291-308.

12. Garn SN, Newton RA. Kinesthetic awareness in subjects with multiple ankle sprains. Phys Ther. 1988;68(11):1667-71. [PMID: 3186791$]$

13. Scully RM, Barnes MR. Physical therapy. Philadelphia (PA): Lippincott Williams \& Wilkins; 1989. p. 825-43.

14. Kinzey SJ, Armstrong CW. The reliability of the StarExcursion Test in assessing dynamic balance. J Orthop Sports Phys Ther. 1998;27(5):356-60. [PMID: 9580895]

15. Hageman PA, Leibowitz JM, Blanke D. Age and gender effects on postural control measures. Arch Phys Med Rehabil. 1995;76(10):961-65. [PMID: 7487439]

16. Tropp H, Odenrick P. Postural control in single-limb stance. J Orthop Res. 1988;6(6):833-39. [PMID: 3171763]
17. Nichols DS. Balance retraining after stroke using force platform biofeedback. Phys Ther. 1997;77(5):553-58. [PMID: 9149764]

18. Rouzier PA. The sports medicine patient advisor. Amherst (MA): Sportsmed Press; 1999. p. 7-11.

19. Hislop HJ, Montgomery J. Muscle testing techniques of manual examination. 7th ed. New York (NY): W. B. Saunders; 2002. p. 2.

20. Duncan PW, Weiner DK, Chandler J, Studenski S. Functional reach: A new clinical measure of balance. J Gerontol. 1990;45(6):M192-97. [PMID: 2229941]

21. Van Deursen RW, Simoneau GG. Foot and ankle sensory neuropathy, proprioception, and postural stability. J Orthop Sports Phys Ther. 1999;29(2):718-26. [PMID: 10612069]

22. Bullock-Saxton JE, Janda V, Bullock MI. The influence of ankle sprain injury on muscle activation during hip extension. Int J Sports Med. 1994;15(6):330-34. [PMID: 7822072]

23. Leanderson J, Eriksson E, Nilsson C, Wykman A. Proprioception in classical ballet dancers. A prospective study of the influence of an ankle sprain on proprioception in the ankle joint. Am J Sports Med. 1996;24(3):370-74. [PMID: 8734890]

Submitted for publication January 2, 2006. Accepted in revised form April 4, 2006. 
